\title{
Prevalence of chromosomal abnormalities and 22q11.2 deletion in conotruncal and non- conotruncal antenatally diagnosed congenital heart diseases in a Chinese population
}

\author{
CW Kong *, Yvonne KY Cheng, William WK To, TY Leung
}

\section{A B S T R A C T}

Introduction: The aim of the present study was to calculate the prevalence of chromosomal abnormalities among antenatally diagnosed congenital heart diseases (CHDs), and the prevalence of $22 \mathrm{q} 11.2$ deletion in those with conotruncal CHDs versus isolated non-conotruncal CHDs.

Methods: All patients with antenatal ultrasound finding of fetal CHDs in two obstetric units in a 5-year period were retrospectively reviewed. Detected CHDs were classified as conotruncal if the malformation involved either the aortic outflow tract or the pulmonary outflow tract; otherwise they were classified as non-conotruncal. Karyotyping, fluorescence in situ hybridisation for $22 \mathrm{q} 11.2$ deletion (22q11FISH), and array comparative genomic hybridisation $(\mathrm{aCGH})$ results were retrieved from patient medical records. The primary outcome was prevalence of chromosomal abnormalities in CHDs. The secondary outcomes were prevalence of $22 \mathrm{q} 11.2$ deletion and its prevalence in conotruncal versus non-conotruncal CHDs.

Results: A total of 254 Chinese patients were diagnosed to have fetal CHDs. In all, 50 (19.7\%)
This article was published on 18 Jan 2019 at www.hkmj.org. of whom all seven had conotruncal CHDs and none had non-conotruncal CHDs $(\mathrm{P}<0.05)$. Conventional karyotyping detected 35 (70\%) cases of the chromosomal abnormalities. The 22q11FISH detected three cases of 22q11.2 deletion; aCGH was performed to detect four cases of 22q11.2 deletion and eight other cases of copy number variations.

Conclusion: Our results suggest that invasive testing for karyotyping is recommended for fetal CHDs. Although the prevalence of 22q11.2 deletion was low, testing for 22q11.2 deletion should be offered for conotruncal CHDs.

\section{Hong Kong Med J 2019;25:6-12 \\ https://doi.org/10.12809/hkmj187552}
${ }^{1}$ CW Kong * MB, ChB, MRCOG, FHKAM (Obstetrics and Gynaecology)
${ }^{2}$ YKY Cheng, MB, ChB, MRCOG, FHKAM (Obstetrics and Gynaecology)
${ }^{1}$ WWK To, FRCOG, MD
${ }^{2}$ TY Leung, FRCOG, MD
1 Department of Obstetrics and Gynaecology, United Christian Hospital, Kwun Tong, Hong Kong
2 Department of Obstetrics and Gynaecology, Prince of Wales Hospital, Shatin, Hong Kong

with seven (2.8\%) patients having 22q11.2 deletion, * Corresponding author: melizakong@gmail.com

New knowledge added by this study

- Prevalence of 22q11.2 deletion in the Chinese population is low.

- Cardiac abnormalities in 22q11.2 deletion are mainly conotruncal cardiac defects.

Implications for clinical practice or policy

- Patients should receive counselling for invasive testing for chromosomal abnormalities in fetal cardiac lesions.

- Testing for 22q11.2 deletion is recommended for conotruncal cardiac defect.

\section{Introduction}

Congenital heart diseases (CHDs) are the commonest congenital malformations at birth and a leading cause of neonatal mortality, with an incidence of around eight in 1000 births. ${ }^{1}$ The reported incidence of chromosomal abnormalities in patients with CHDs differs between infants and fetuses, as well as among different series and studies, ranging from $9 \%$ to $18 \% .^{2-7}$ Many previous studies have typically only included major aneuploidies as chromosomal abnormalities; other chromosomal aberrations, such as $22 \mathrm{q} 11.2$ deletion or other microdeletions, were not investigated. The availability of new cytogenetic and molecular technologies, such as specific fluorescence in situ hybridisation (FISH) probes, array comparative genomic hybridisation $(\mathrm{aCGH}),{ }^{8}$ or sophisticated genome sequencing methods, ${ }^{9,10}$ has increased the identified contribution of chromosomal abnormalities.

The frequency of 22q11.2 deletions among all cases of CHDs has been estimated to be around 2\% to $5.7 \% .{ }^{11}$ The prevalence of $22 \mathrm{q} 11.2$ deletions in the 
Chinese population has not been well documented. However, recent studies have shown that the condition is likely to be underdiagnosed in adult Chinese populations, as recognition of clinical and dysmorphic features could be unreliable..$^{12}$ The most frequently encountered CHDs in this syndrome are conotruncal CHDs that involve the pulmonary or aortic outflow tracts. However, 22q11.2 deletions are also associated with isolated non-conotruncal CHDs. ${ }^{13,14}$

The objective of this study was to calculate the prevalence of chromosomal abnormalities among antenatally diagnosed CHDs, and the prevalence of 22q11.2 deletion in those with conotruncal CHDs versus isolated non-conotruncal CHDs.

\section{Methods}

All pregnant patients with antenatal ultrasound finding of fetal CHDs from July 2012 to June 2017 in two maternal fetal medicine referral centres, United Christian Hospital and Prince of Wales Hospital, Hong Kong, were retrospectively retrieved from the obstetric ultrasound database. Non-Chinese patients were excluded from this cohort. The detected CHDs were classified as conotruncal if the malformation involved either the aortic outflow tract or the pulmonary outflow tract; otherwise, they were classified as non-conotruncal. According to the protocol of these two hospitals, pregnant patients with antenatal ultrasound findings of CHDs were offered invasive testing for karyotyping. Self-financed aCGH was recommended to the patient; if she declined aCGH, FISH for 22q11.2 deletion (22q11FISH) was offered free of charge. The aCGH, FISH, and karyotype of patients from United Christian Hospital were sent to the prenatal diagnostic laboratory of Tsan Yuk Hospital; those of patients from Prince of Wales Hospital were sent to the prenatal diagnostic laboratory of the Chinese University of Hong Kong. NimbleGen CGX 135k (Roche, Basel, Switzerland) and CGX v2 60k (PerkinElmer, Waltham [MA], US) oligonucleotide arrays were used in the aCGH studies in the Tsan Yuk Hospital from July 2012 to March 2014 and from March 2014 to June 2017, respectively. Copy number variations (CNVs) were categorised as previously reported by Kan et al. ${ }^{15} \mathrm{~A}$ customised $44 \mathrm{k}$ Fetal Chip v1.0 and a 60k Fetal Chip v2.0 (Agilent Technologies, Inc, Santa Clara [CA], US) were used in the Chinese University of Hong Kong for the aCGH studies from July 2012 to November 2013 and from December 2013 to June 2017, respectively. The CNVs were categorised as previously reported by Leung et al. ${ }^{16}$

The aCGH, 22q11FISH, and karyotyping results were reviewed from patient medical records. The prevalence of chromosomal abnormalities in these antenatally diagnosed CHDs fetuses, specifically the prevalence of 22q11.2 deletion, was calculated

\section{華人人口中產前診斷錐幹和非錐幹先天性心臟病 的染色體異常和 $22 q 11.2$ 區域缺失的現患率 江采華、鄭昆瑜、杜榮基、梁德楊}

引言: 本研究旨在計算產前診斷先天性心臟病病例中染色體異常的現 患率, 以及錐幹先天性心臟病和非錐幹先天性心臟病病例中 $22 q 11.2$ 區域缺失的現患率

方法：分析5年內於兩間醫院產科部門經產前超聲檢查發現胎兒先天 性心臟病的患者。畸形涉及主動脈流出道或肺流出道歸類為錐幹先天 性心臟病, 其他則歸類為非錐幹先天性心臟病。從患者醫療記錄中檢 索核型分析、針對 $22 \mathrm{q} 11.2$ 區域缺失檢測的熒光原位雜交分析, 以及 陣列比較基因組雜交分析結果。主要結果是先天性心臟病染色體異常 的現患率。次要結果是 $22 \mathrm{q} 11.2$ 區域缺失的現患率, 並將錐幹和非錐 幹先天性心臟病的22q11.2區域現患率作比較。

結果：共 254 名華籍患者被診斷胎兒先天性心臟病, 當中50例 ( $19.7 \%)$ 發現染色體異常, 其中7例 $(2.8 \%)$ 出現 22 q 11.2 區域 缺失, 全屬錐幹先天性心臟病, 未發現非錐幹先天性心臟病病例 $(\mathrm{P}<0.05)$ 。常規核型分析檢測35例（70\%）染色體異常。熒光原 位雜交檢測 3 例 $22 \mathrm{q} 11.2$ 區域缺失; 陣列比較基因組雜交則檢測 4 例 22q11.2區域缺失和 8 例其他染色體拷貝數變異。

結論：建議對懷有先天性心臟病胎兒的婦女進行入侵性核型分析測 試。儘管 22 q 11.2 區域缺失的現患率較低, 但有需要對錐幹先天性心 藏病進行相關檢測

and compared between the conotruncal CHDs and the non-conotruncal CHDs. The primary outcome was the prevalence of chromosomal abnormalities in CHDs. The secondary outcomes were the total prevalence of 22q11.2 deletion in conotruncal CHDs compared with that in non-conotruncal CHDs.

The SPSS (Windows version 20.0; IBM Corp, Armonk [NY], US) was used for data entry and analysis. Comparison of categorical variables between the conotruncal and non-conotruncal groups was analysed by Chi squared test or Fisher exact test where appropriate. A P value of $<0.05$ was considered statistically significant.

The Strengthening the Reporting of Observational Studies in Epidemiology (STROBE) statement was used in the preparation of this article. ${ }^{17}$

\section{Results}

From July 2012 to June 2017, there were 54802 deliveries in United Christian Hospital and Prince of Wales Hospital, among which $264(0.48 \%)$ patients were diagnosed to have fetal CHDs by antenatal ultrasound scan. Of these, 254 (96.2\%) patients were Chinese and were recruited for final analysis. The mean ( \pm standard deviation) maternal age was $32.3 \pm$ 4.9 years, with 151 (59.4\%) patients being nulliparous. The mean gestational age at diagnosis of fetal CHDs 
TABLE I. Prevalence of conotruncal and non-conotruncal defects and associated chromosomal abnormalities

\begin{tabular}{|c|c|c|}
\hline Cardiac defect & No. of cases & $\begin{array}{l}\text { Presence of } \\
\text { chromosomal } \\
\text { abnormalities }\end{array}$ \\
\hline Conotruncal defects $(n=160)$ & & 25/129 (19.4\%) \\
\hline Tetralogy of Fallot & $40(25.0 \%)$ & $10 / 37(27.0 \%)$ \\
\hline Right-sided aortic arch & $23(14.4 \%)$ & $3 / 19(15.8 \%)$ \\
\hline Pulmonary stenosis/atresia & $18(11.3 \%)$ & $0 / 11$ \\
\hline Persistent left superior vena cava & $18(11.3 \%)$ & $1 / 8(12.5 \%)$ \\
\hline Transposition of great arteries & $16(10.0 \%)$ & $2 / 15(13.3 \%)$ \\
\hline Coarctation of aorta & $14(8.8 \%)$ & $3 / 13(23.1 \%)$ \\
\hline Double outlet of right ventricle & $13(8.1 \%)$ & $3 / 13(23.1 \%)$ \\
\hline Aortic stenosis & $5(3.1 \%)$ & $1 / 2(50.0 \%)$ \\
\hline Double inlet of left ventricle & $4(2.5 \%)$ & $0 / 4$ \\
\hline Aberrant right subclavian artery & $4(2.5 \%)$ & $0 / 2$ \\
\hline Truncus arteriosus & $2(1.3 \%)$ & $0 / 2$ \\
\hline Interrupted aortic arch & $2(1.3 \%)$ & $2 / 2(100.0 \%)$ \\
\hline Common inlet right ventricle & $1(0.6 \%)$ & $0 / 1$ \\
\hline Non-conotruncal defects $(n=94)$ & & $25 / 78(32.1 \%)$ \\
\hline Ventricular septal defect & $36(38.3 \%)$ & $5 / 22(22.7 \%)$ \\
\hline Hypoplastic left heart syndrome & $22(23.4 \%)$ & $7 / 22(31.8 \%)$ \\
\hline Atrioventricular septal defect & $17(18.1 \%)$ & $8 / 17(47.1 \%)$ \\
\hline Tricuspid valve dysplasia & $5(5.3 \%)$ & $1 / 5(20.0 \%)$ \\
\hline Epstein anomaly & $4(4.3 \%)$ & $0 / 3$ \\
\hline Dextrocardia & $2(2.1 \%)$ & $1 / 2(50.0 \%)$ \\
\hline Atrial septal defect & $2(2.1 \%)$ & $0 / 2$ \\
\hline Rhabdomyoma & $2(2.1 \%)$ & $0 / 1$ \\
\hline Cardiomegaly & $2(2.1 \%)$ & $2 / 2(100.0 \%)$ \\
\hline Hypoplastic right heart syndrome & $1(1.1 \%)$ & $0 / 1$ \\
\hline Mitral valve dysplasia & $1(1.1 \%)$ & $1 / 1(100.0 \%)$ \\
\hline
\end{tabular}

by ultrasound was $20.4 \pm 2.9$ weeks. Within the total cohort of 254 patients with fetal CHDs, 160 (63.0\%) were classified into the conotruncal group, while $94(37.0 \%)$ were classified into the nonconotruncal group. The prevalence of the various types of conotruncal and non-conotruncal CHDs and the prevalence of chromosomal abnormalities are listed in Table 1. Fourty-one (16.1\%) patients had other structural abnormalities found in antenatal ultrasound apart from CHDs.

Chromosomal analysis and karyotyping was done in 207 (81.5\%) patients; of them, aCGH was performed in $146(70.5 \%)$ and 22q11FISH was performed in 61 (29.5\%). The remaining 47 patients refused chromosomal analysis. In the group of 207 fetuses with karyotype performed, 50 (24.2\%) were found to have chromosomal abnormalities; trisomy 21 and trisomy 18 accounted for $42.0 \%$ of all these abnormalities. The different types of chromosomal abnormalities are shown in Table 2 . Of the 50 cases with chromosomal abnormalities, 35 (70\%) were detected by conventional karyotyping. Three cases of $22 \mathrm{q} 11.2$ deletion were detected by FISH; aCGH detected another four cases of 22q11.2 deletion and eight cases of other CNVs, as shown in Table 3. The prevalence of chromosomal abnormalities in fetuses without extracardiac abnormalities was 29 of 168 (17.3\%), whereas that in fetuses with extracardiac abnormalities was 21 of 39 (53.8\%). The prevalence of chromosomal abnormalities in non-conotruncal CHDs was 25 of 78 (32.1\%) which was significantly higher than that in conotruncal CHDs (25 of 129; 19.4\%) $[\mathrm{P}=0.04]$. All seven patients with $22 \mathrm{q} 11.2$ deletion were found in the group of conotruncal CHDs and no patients with 22q11.2 deletion were found in the group of non-conotruncal CHDs $(\mathrm{P}<0.05)$. The details of these seven cases are shown in Table 4.

Among the whole cohort of 254 patients with prenatal ultrasound diagnosis of CHDs, 101 (39.8\%) patients had their pregnancies terminated. There were 134 (52.8\%) live births, nine (3.5\%) neonatal deaths, and four (1.6\%) intrauterine deaths or miscarriages. Six (2.4\%) patients were lost for followup and could not be contacted for their pregnancy outcomes.

\section{Discussion}

The data from this cohort demonstrated that $24.2 \%$ of fetuses with CHDs detected by antenatal ultrasound were found to have chromosomal abnormalities. The frequency of chromosomal abnormality in fetuses with CHDs is much higher than the frequency of such abnormalities in infants, because a large portion of these fetuses are terminated. A 2004 review found that up to $33 \%$ of fetal CHDs were associated with chromosomal abnormalities ${ }^{1}$; this is much higher than the prevalence in our cohort for two reasons. Firstly, subtle defects such as right-sided aortic arch, persistent left superior vena cava, and aberrant right subclavian artery were not included as CHDs in the previous review. With advances in the ultrasonography resolution, these subtle defects are detected with increasing frequency in recent years. In the current cohort, up to 45 cases belong in this category, but only four of them were found to have chromosomal abnormalities. Secondly, most of our patients had combined biochemical screening or cell-free DNA test in the first trimester for Down syndrome screening. If the screening test was positive, an invasive test was performed and management offered accordingly. Fetal CHDs may not be detectable at that early gestation, and obstetricians may not have been focused on detecting cardiac abnormalities at that time. Therefore, the true prevalence of chromosomal abnormalities in CHDs in fetuses with common aneuploidies may be underestimated in our cohort. 
TABLE 2. Prevalence of chromosomal abnormalities in conotruncal, non-conotruncal, and all cardiac defects

\begin{tabular}{lccc}
\hline Chromosomal abnormalities & $\begin{array}{c}\text { Conotruncal defects } \\
(\mathbf{n = 1 2 9 )}\end{array}$ & $\begin{array}{c}\text { Non-conotruncal defects } \\
(\mathbf{n = 7 8 )}\end{array}$ & $\begin{array}{c}\text { All cardiac defects } \\
(\mathbf{n = 2 0 7})\end{array}$ \\
\hline None & $104(80.6 \%)$ & $53(67.9 \%)$ & $157(75.8 \%)$ \\
Trisomy 18 & $2(1.6 \%)$ & $9(11.5 \%)$ & $11(5.3 \%)$ \\
Trisomy 21 & $2(1.6 \%)$ & $8(10.3 \%)$ & $10(4.8 \%)$ \\
Deletions except 22q11.2 & $4(3.1 \%)$ & $4(5.1 \%)$ & $8(3.9 \%)$ \\
\hline 22q11.2 Deletion & $7(5.4 \%)$ & 0 & $7(3.4 \%)$ \\
Unbalanced translocation & $3(2.3 \%)$ & 0 & $3(1.4 \%)$ \\
Duplications & $2(1.6 \%)$ & $1(1.3 \%)$ & $3(1.4 \%)$ \\
Inversions & $3(2.3 \%)$ & 0 & $3(1.4 \%)$ \\
Trisomy 13 & 0 & $1(1.3 \%)$ & $1(0.5 \%)$ \\
Turner syndrome & $1(0.8 \%)$ & 0 & $1(0.5 \%)$ \\
Triploidy & 0 & $1(1.3 \%)$ & $1(0.5 \%)$ \\
Others & $1(0.8 \%)$ & $1(1.3 \%)$ & $2(1.0 \%)$ \\
\hline
\end{tabular}

TABLE 3. Additional copy number variations detected by array comparative genomic hybridisation apart from 22ql I.2 deletion

\begin{tabular}{|c|c|c|c|c|c|c|}
\hline Fetus & ISCN nomenclature (hg19) & $\begin{array}{l}\text { Size of } \\
\text { deletion }\end{array}$ & Allele origin & Pathogenic & $\begin{array}{c}\text { Cardiac } \\
\text { abnormalities }\end{array}$ & $\begin{array}{l}\text { Pregnancy } \\
\text { outcome }\end{array}$ \\
\hline Case 1 & $\begin{array}{l}21 q 11.1 q 11.2(13910574 \times 2,13919822-15 \\
707444 \times 3,15784350 \times 2) \text { mat }\end{array}$ & $1.8 \mathrm{Mb}$ & Maternally inherited & VOUS & TOF & Live birth \\
\hline Case 2 & 15q26.3 (99 $646658-100160$ 168) × 3 mat & $514 \mathrm{~kb}$ & Maternally inherited & VOUS & TGA & NND \\
\hline Case 3 & Xq28 (154 120 738-154 494 269) × 1 mat & $374 \mathrm{~kb}$ & Maternally inherited & $\begin{array}{c}\text { Carrier of pathogenic } \\
\text { variant }\end{array}$ & AVSD & TOP \\
\hline Case 4 & $7 q 36.1 q 36.2(150052506-152771624) \times 3$ & $2.7 \mathrm{Mb}$ & De novo & Pathogenic & Cardiomegaly & Live birth \\
\hline Case 5 & $15 q 15.1(40476073-42039170) \times 1$ & $1.6 \mathrm{Mb}$ & De novo & Pathogenic & TOF & Miscarriage \\
\hline Case 6 & Xp22.2 (10 667 354-10 715 946) × 0 mat & $48.6 \mathrm{~kb}$ & Maternally inherited & Pathogenic & HLHS & TOP \\
\hline Case 7 & $7 q 11.22 q 11.23(67591191-73667513) \times 1$ & $6.1 \mathrm{Mb}$ & De novo & $\begin{array}{l}\text { Pathogenic (Williams- } \\
\text { Beuren syndrome) }\end{array}$ & Aortic stenosis & Stillbirth \\
\hline Case 8 & $22 q 13.31 q 13.33(47222964-51219009) \times 1$ & $4.0 \mathrm{Mb}$ & De novo & $\begin{array}{l}\text { Pathogenic (Phelan- } \\
\text { McDermid syndrome) }\end{array}$ & TGA & TOP \\
\hline
\end{tabular}

Abbreviations: AVSD = atrioventricular septal defect; HLHS = hypoplastic left heart syndrome; ISCN = International System for Human Cytogenetic Nomenclature; NND = neonatal death;TGA = transposition of great arteries; TOF = tetralogy of Fallot; TOP = termination of pregnancy; VOUS = variant of uncertain significance

TABLE 4. Copy number variations detected by array comparative genomic hybridisation, clinical features, and pregnancy outcomes for seven fetuses with $22 q$ I I.2 deletion

\begin{tabular}{|c|c|c|c|c|c|c|c|c|c|}
\hline Fetus & $\begin{array}{l}\text { ISCN nomenclature } \\
\text { (hg19) }\end{array}$ & $\begin{array}{c}\text { Size } \\
\text { of the } \\
\text { deletion }\end{array}$ & $\begin{array}{c}\text { CHDs } \\
\text { genes } \\
\text { involved }\end{array}$ & $\begin{array}{l}\text { Allele } \\
\text { origin }\end{array}$ & $\begin{array}{c}\text { Cardiac } \\
\text { abnormalities }\end{array}$ & $\begin{array}{l}\text { Cleft } \\
\text { palate }\end{array}$ & $\begin{array}{c}\text { Absent } \\
\text { thymus/thymic } \\
\text { hypoplasia }\end{array}$ & $\begin{array}{l}\text { Developmental } \\
\text { delay }\end{array}$ & $\begin{array}{l}\text { Pregnancy } \\
\text { outcome }\end{array}$ \\
\hline Case 1 & N/A & $\mathrm{N} / \mathrm{A}$ & $\mathrm{N} / \mathrm{A}$ & De novo & IAA & No & Yes & $\mathrm{N} / \mathrm{A}$ & TOP \\
\hline Case 2 & $\mathrm{~N} / \mathrm{A}$ & N/A & $\mathrm{N} / \mathrm{A}$ & De novo & TOF & No & Yes & $\begin{array}{l}\text { None at } 22 \text {-month } \\
\text { follow-up }\end{array}$ & Live birth \\
\hline Case 3 & N/A & N/A & N/A & De novo & IAA & No & Yes & N/A & TOP \\
\hline Case 4 & $\begin{array}{l}22 q 11.21(18909032- \\
21357982) \times 1\end{array}$ & $2.4 \mathrm{Mb}$ & TBX1 & De novo & TOF & No & No & $\mathrm{N} / \mathrm{A}$ & TOP \\
\hline Case 5 & $\begin{array}{l}22 q 11.21(18909032- \\
21357982) \times 1\end{array}$ & $2.4 \mathrm{Mb}$ & $T B X 1$ & De novo & TOF & No & No & $\mathrm{N} / \mathrm{A}$ & TOP \\
\hline Case 6 & $\begin{array}{l}22 q 11.21(18909032- \\
21801661) \times 1\end{array}$ & $2.9 \mathrm{Mb}$ & TBX1 & De novo & TOF & No & Yes & $\mathrm{N} / \mathrm{A}$ & TOP \\
\hline Case 7 & $\begin{array}{l}22 q 11.21(18915409- \\
18976958) \times 1\end{array}$ & $61 \mathrm{~kb}$ & DGCR5 & $\begin{array}{l}\text { Maternally } \\
\text { inherited }\end{array}$ & RAA & No & No & $\mathrm{N} / \mathrm{A}$ & $\begin{array}{l}\text { NND on day } 8 \\
\text { due to sepsis }\end{array}$ \\
\hline
\end{tabular}

Abbreviations: CHDs = congenital heart diseases; IAA = interrupted aortic arch; ISCN = International System for Human Cytogenetic Nomenclature; N/A

= not available; $\mathrm{NND}=$ neonatal death; RAA = right-sided aortic arch;TOF = tetralogy of Fallot;TOP = termination of pregnancy 
In the present study, non-conotruncal CHDs were found to have a higher prevalence of chromosomal abnormalities than conotruncal CHDs. Some types of CHDs, such as atrioventricular septal defects and hypoplastic left heart syndrome, are associated with a higher prevalence of chromosomal abnormalities than others, whereas some types of CHDs, such as truncus arteriosus, are rarely associated with chromosomal abnormalities. Invasive testing for karyotyping is generally recommended for antenatally diagnosed CHDs, as the prevalence of chromosomal abnormalities is up to $24.2 \%$. Non-invasive prenatal testing may be performed instead of karyotyping for some isolated cardiac abnormalities, such as isolated small ventricular septal defects (VSDs), persistent left superior vena cava, and aberrant right subclavian artery, when the purpose is to exclude major aneuploidies such as trisomy 21.

The 22q11.2 deletion syndrome is also called DiGeorge syndrome or velo-cardio-facial syndrome. Most patients with this syndrome have a 1.5- to 3-Mb hemizygous deletion at chromosome 22q11.2 causing $T B X 1, C R K L$, and MAPK1 gene haploinsufficiency. ${ }^{18}$ This syndrome is characterised by cardiac defects, cleft palate, thymic hypoplasia, immune deficiency, hypocalcaemia, and learning difficulties. ${ }^{19}$ It has more than 180 associated phenotypic features, with very variable genotype-phenotype correlations. Congenital heart diseases remain one of the most important clinical manifestations, and are present in $75 \%$ of patients with $22 q 11.2$ deletion..$^{19}$ The most common abnormalities are conotruncal CHDs, among which tetralogy of Fallot (TOF) is the most common. ${ }^{14,20}$ However, 22q11.2 deletion has also been reported in patients with non-conotruncal CHDs such as isolated VSD. ${ }^{13,14}$ In a cross-sectional survey of 392 patients with CHDs, the prevalence of 22q11.2 deletion was only $1.27 \%$. Four out of the five confirmed patients had conotruncal CHDs (interrupted aortic arch, truncus arteriosus, and TOF); the other patient had non-conotruncal CHDs (VSD plus atrial septal defect). Two patients had congenital extracardiac anomaly (one with arched palate and micrognathia and one with hypertelorism). ${ }^{21}$ In a survey of 125 consecutive children in South Africa with CHDs, the prevalence of 22q11.2 deletions was $4.8 \%$. The cardiac abnormalities in these confirmed patients included four with conotruncal CHDs (tricuspid atresia with interrupted aortic arch, tricuspid atresia with rightsided aortic arch, TOF, and VSD with right-sided aortic arch), but also two isolated VSDs. ${ }^{22}$ The above two studies suggest that most patients with 22q11.2 deletions have conotruncal CHDs; although nonconotruncal CHDs are possible, the prevalence is low.

The prevalence of 22q11.2 deletions in the
Chinese population has not been well documented. A study of 113 Chinese fetuses with CHDs found that the frequency of 22q11.2 deletion was $5.3 \%{ }^{23}$ A recent study surveyed the prevalence of undiagnosed 22q11.2 deletions in 156 adult Hong Kong Chinese patients with conotruncal CHDs by screening for 22q11.2 deletion syndrome using fluorescence polymerase chain reaction and FISH. Eighteen (11.5\%) patients were diagnosed with 22q11.2 deletion syndrome, translating into one previously unrecognised diagnosis of 22q11.2 deletion syndrome in every 10 adults with conotruncal CHDs. Extracardiac manifestations in these affected individuals included velopharyngeal incompetence or cleft palate (44\%), hypocalcaemia (39\%), neurodevelopmental anomalies (33\%), thrombocytopenia (28\%), psychiatric disorders (17\%), epilepsy (17\%), and hearing loss (17\%). Those authors concluded that underdiagnosis in Chinese adults is common and recognition of facial dysmorphic features can be affected by age and ethnicity. Facial dysmorphic features may not be reliably recognised in adult patients with CHDs in the clinical setting; therefore, referral for genetic evaluation and molecular testing for 22q11.2 deletion syndrome should be offered to patients with conotruncal CHDs. ${ }^{12}$

In contrast, in a small Chinese series, the frequency of 22q11.2 deletion in three Chinese ethnic groups (Tai, Bai, and Han people) with 19 sporadic CHDs was studied using genotype and haplotype analysis with D22S420 in 11 consecutive polymorphic microsatellite markers. Within this cohort, deletions at D22S944 were found in two of four patients with TOF, one of five patients with VSD, and one of five patients with patent ductus arteriosus. Those authors concluded that sporadic 22q11.2 deletion could be detected in isolated TOF, VSD, and patent ductus arteriosus in Chinese ethnic groups without relevant family history of CHDs. ${ }^{13}$ The present study includes a larger sample size (207 fetuses) than the previous two Chinese studies, but the detected prevalence of 22q11.2 deletion was only $3.4 \%$. In addition, all seven fetuses with confirmed 22q11.2 deletion in the present study had conotruncal CHDs; none had non-conotruncal CHDs or isolated VSD. The inclusion of patent ductus arteriosus in the second study as CHDs is inconsistent with other studies. Therefore those findings of 22q11.2 deletion associated with isolated CHDs should be further evaluated in other populations.

The prevalence of 22q11.2 deletion in the present study was $3.4 \%$ (7/207), which is comparable to that reported in the literature. Because all patients had either 22q11FISH or aCGH testing, the possibility of underdiagnosis was minimised. The cardiac abnormalities identified in the confirmed cases were all conotruncal CHDs typical of 22q11.2 
deletion syndrome. The deletions were not found in any cases with non-conotruncal CHDs, suggesting that the occurrence of 22q11.2 deletion in nonconotruncal CHDs in the local population is very low.

Array comparative genomic hybridisation is a molecular cytogenetic technique to detect any CNVs within the genome. A systematic review and metaanalysis on the use of aCGH on fetal CHDs that included 1131 cases showed that the incremental yield of aCGH in detecting CNVs after karyotyping and 22 q11FISH analysis was $7 \%$. An incremental yield of $12 \%$ was found when $22 \mathrm{q} 11.2$ deletion cases were included ${ }^{24}$ In the present study, aCGH detected four cases of 22q11.2 deletion and eight additional cases of CNVs. On the basis of the deletion size in the four cases of 22q11.2 deletion, three should also be detected by 22q11FISH; only the 61-kb deletion would not be detectable by FISH. Therefore, if all patients in our cohort had karyotyping only without 22q11FISH, aCGH would have an incremental yield of $6.0 \%(12 / 207)$. If all our patients had karyotyping and 22q11FISH as first line, then aCGH would have a further incremental yield of $4.3 \%(9 / 207)$. This incremental rate for aCGH was lower than that reported previously. ${ }^{24}$ For patients in Hong Kong, aCGH is a self-financed option. If fetal CHDs are detected antenatally, invasive testing with karyotype and aCGH is offered to the patient on the basis of the potential incremental yield of aCGH. In the present study, counselling for patients whose fetus has Williams-Beuren syndrome or Phelan-McDermid syndrome would be different from that for patients whose fetus has isolated cardiac defects, as there would be other extracardiac manifestation such as mental retardation. However, if patient declines selfpaid aCGH, 22q11FISH should be offered in addition to conventional karyotyping, because karyotyping cannot readily detect $22 \mathrm{q} 11.2$ deletion.

\section{Limitations}

This study may have underestimated the prevalence of chromosomal abnormalities, because 47 of our patients did not have chromosomal analysis performed, 30 of whom were counselled as having minor cardiac abnormalities or were normal variants (14 fetuses had isolated small VSD, 10 had persistent left superior vena cava, four had right-sided aortic arch, and two had aberrant right subclavian artery). However, none of the babies were suspected or diagnosed to have chromosomal abnormalities or DiGeorge syndrome after clinical assessment by paediatrician after birth. Therefore, we assumed that there were no major clinically significant chromosomal abnormalities in these babies.

Although the prevalence of 22q11.2 deletion is low, testing for 22q11.2 deletion should be offered for fetuses with conotruncal CHDs. Array comparative genomic hybridisation has an additional incremental yield of around $5 \%$ on other microdeletions apart from 22q11.2 deletion, and should be offered in addition to karyotyping and 22q11FISH.

\section{Author contributions}

All authors had full access to the data, contributed to the study, approved the final version for publication, and take responsibility for its accuracy and integrity.

Concept or design of the study: CW Kong, WWK To.

Acquisition of data: CW Kong, YKY Cheng.

Analysis or interpretation of data: CW Kong, YKY Cheng, WWK To, TY Leung.

Drafting of the manuscript: CW Kong.

Critical revision for important intellectual content: YKY Cheng, WWK To, TY Leung.

\section{Conflicts of interest}

All authors have disclosed no conflicts of interest.

\section{Declaration}

The findings of this study were presented as poster presentation in the 17th World Congress in Fetal Medicine, Athens, Greece, 24-28 June 2018.

\section{Funding/support}

This research received no specific grant from any funding agency in the public, commercial or not-for-profit sectors.

\section{Ethics approval}

Ethics approval for this study was granted by the Kowloon Central/ Kowloon East Research Ethics Committee (KC/KE17-0183/ER-3) and the Joint CUHK-NTEC Clinical Research Ethics Committee (NTEC-2017-0336). As this study was a retrospective review, the need for individual patient consent was waived by the above two research ethics committees.

\section{References}

1. Wimalasundera RC, Gardiner HM. Congenital heart disease and aneuploidy. Prenat Diagn 2004;24:1116-22.

2. Hartman RJ, Rasmussen SA, Botto LD, et al. The contribution of chromosomal abnormalities to congenital heart defects: a population-based study. Pediatr Cardiol 2011;32:1147-57.

3. Ferencz C, Neill CA, Boughman JA, Rubin JD, Brenner JI, Perry LW. Congenital cardiovascular malformations associated with chromosome abnormalities: an epidemiologic study. J Pediatr 1989;114:79-86.

4. Kidd SA, Lancaster PA, McCredie RM. The incidence of congenital heart defects in the first year of life. J Paediatr Child Health 1993;29:344-9.

5. Harris JA, Francannet C, Pradat P, Robert E. The epidemiology of cardiovascular defects, part 2: a study based on data from three large registries of congenital malformations. Pediatr Cardiol 2003;24:222-35.

6. Schellberg R, Schwanitz G, Grävinghoff L, et al. New trends in chromosomal investigation in children with cardiovascular malformations. Cardiol Young 2004;14:6229.

7. Reller MD, Strickland MJ, Riehle-Colarusso T, Mahle 
WT, Correa A. Prevalence of congenital heart defects in metropolitan Atlanta, 1998-2005. J Pediatr 2008;153:807-13.

8. Geng J, Picker J, Zheng Z, et al. Chromosome microarray testing for patients with congenital heart defects reveals novel disease causing loci and high diagnostic yield. BMC Genomics 2014;15:1127.

9. Zhu X, Li J, Ru T, et al. Identification of copy number variations associated with congenital heart disease by chromosomal microarray analysis and next-generation sequencing. Prenatal Diagn 2016;36:321-7.

10. Zaidi S, Brueckner M. Genetics and genomics of congenital heart disease. Circ Res 2017;120:923-40.

11. Rosa RF, Pilla CB, Pereira VL, et al. 22q11.2 Deletion syndrome in patients admitted to a cardiac pediatric intensive care unit in Brazil. Am J Med Genet A 2008;146A:1655-61.

12. Liu AP, Chow PC, Lee PP, et al. Under-recognition of 22q11.2 deletion in adult Chinese patients with conotrunal anomalies: implications in transitional care. Eur J Med Genet 2014;57:306-11.

13. Jiang L, Duan C, Chen B, et al. Association of 22q11 deletion with isolated congenital heart disease in three Chinese ethnic groups. Int J Cardiol 2005;105:216-23.

14. Wozniak A, Wolnik-Brzozowska D, Wisniewska M, et al. Frequency of 22q11.2 microdeletion in children with congenital heart defects in western Poland. BMC Pediatr 2010;10:88.

15. Kan AS, Lau ET, Tang WF, et al. Whole-genome array $\mathrm{CGH}$ evaluation for replacing prenatal karyotyping in Hong Kong. PLoS One 2014;9:e87988.

16. Leung TY, Vogel I, Lau TK, et al. Identification of submicroscopic chromosomal aberrations in fetuses with increased nuchal translucency and apparently normal karyotype. Ultrasound Obstet Gynecol 2011;38:314-9.

17. von Elm E, Altman DG, Egger M, Pocock SJ, Gøtzsche PC, Vandenbroucke JP; STROBE Initiative. The Strengthening the Reporting of Observational Studies in Epidemiology (STROBE) statement: guidelines for reporting observational studies. Epidemiology 2007;18:800-4.

18. Koczkowska M, Wierzba J, Śmigiel R, et al. Genomic findings in patients with clinical suspicion of 22q11.2 deletion syndrome. J Appl Genet 2017;58:93-8.

19. Digilio M, Marino B, Capolino R, Dallapiccola B. Clinical manifestations of Deletion 22q11.2 syndrome (DiGeorge/ Velo-Cardio-Facial syndrome). Images Paediatr Cardiol 2005;7:23-34.

20. Lammer EJ, Chak JS, Iovannisci DM, et al. Chromosomal abnormalities among children born with conotruncal cardiac defects. Birth Defects Res A Clin Mol Teratol 2009;85:30-5.

21. Huber J, Peres VC, de Castro AL, et al. Molecular Screening for 22Q11.2 deletion syndrome in patients with congenital heart disease. Pediatr Cardiol 2014;35:1356-62.

22. De Decker R, Bruwer Z, Hendricks L, Schoeman M, Schutte G, Lawrenson J. Predicted v. real prevalence of the 22q11.2 deletion syndrome in children with congenital heart disease presenting to Red Cross War Memorial Children's Hospital, South Africa: a prospective study. S Afr Med J 2016;106(6 Suppl 1):S82-6.

23. Lv W, Wang S. Detection of chromosomal abnormalities and the 22q11 microdeletion in fetuses with congenital heart defects. Mol Med Rep 2014;10:2465-70.

24. Jansen FA, Blumenfeld YJ, Fisher A, et al. Array comparative genomic hybridization and fetal congenital heart defects: a systematic review and meta-analysis. Ultrasound Obstet Gynecol 2015;45:27-35. 